\title{
Transmural conduction time in an early repolarization syndrome model
}

\author{
NAMSIK YOON, HYUNG KI JEONG, KI HONG LEE, HYUNG WOOK PARK and JEONG GWAN CHO
}

\author{
Department of Cardiovascular Medicine, Heart Center of Chonnam National University Hospital, \\ Chonnam National University Medical School, Chonnam National University, Dong-gu, Gwangju 61469, Republic of Korea
}

Received January 5, 2020; Accepted June 17, 2020

DOI: 10.3892/etm.2020.9061

\begin{abstract}
In the pathological aspect of $\mathrm{J}$ wave syndrome, delayed depolarization is defined as the difference in local conduction velocity of the ventricular myocardium. If polymorphic ventricular tachycardia is induced without local conduction velocity heterogeneity, this contradicts the delayed depolarization theory. In the present study, the transmural conduction time at was evaluated at several transmural locations in a canine early repolarization model. The transmural pseudo-electrocardiogram and endocardial/epicardial action potentials were recorded from coronary-perfused canine left ventricular wedge preparations $(n=18)$. The $I_{\text {to }}$ agonist NS5806 $(9-10 \mu \mathrm{M}), \mathrm{Ca}^{2+}$ channel blocker verapamil $(2 \mu \mathrm{M})$ and acetylcholine (ACh) $(2 \mu \mathrm{M})$ were used to pharmacologically mimic early repolarization syndrome genotypes. The transmural conduction times were measured at five fixed epicardial unipolar electrodes before and after the perfusion of provocative agents. The transmural conduction time was defined as the time from endocardial stimulation to the maximal negative deflection $(\mathrm{d} V / \mathrm{d} t)$ of the endocardial electrogram at the unipolar electrode. Polymorphic ventricular tachycardia developed in $14 / 18$ preparations. In the transmembrane action potentials, there was no definite delayed phase 0 upstroke in any induced polymorphic ventricular tachycardia preparations. In all preparations, the transmural conduction time increased significantly after perfusing the $\mathrm{I}_{\text {to }}$ agonist NS5806, verapamil and Ach; however, the increase was only $2.6 \pm 0.4 \mathrm{msec}$, and dispersion of the transmural conduction time did not exhibit significant heterogeneity (7.16 \pm 0.93 vs. $7.76 \pm 1.21 \mathrm{msec} ; \mathrm{P}=0.240$ ). In the early repolarization model, polymorphic ventricular tachycardia was induced without
\end{abstract}

Correspondence to: Professor Jeong Gwan Cho, Department of Cardiovascular Medicine, Heart Center of Chonnam National University Hospital, Chonnam National University Medical School, Chonnam National University, 42 Jaebongro, Dong-gu, Gwangju 61469, Republic of Korea

E-mail: NSAIDs77@hitel.net

Key words: early repolarization syndrome, conduction velocity, ventricular tachycardia any regional conduction velocity heterogeneity. This finding suggests that local depolarization heterogeneity would not be a major contributor to the generation of ventricular arrhythmia in the early repolarization syndrome wedge preparation model.

\section{Introduction}

Early repolarization patterns are characterized by $\mathbf{J}$ point elevation, distinct $\mathbf{J}$ waves combined with or without ST-segment elevation or slurring in the terminal portion of the QRS wave in inferolateral electrocardiogram (ECG) leads. An early repolarization pattern on ECGs has traditionally been considered to be benign $(1,2)$; however, according to previous experimental studies, a more pathological prognosis has been suggested $(3,4)$, and subsequently confirmed in clinical studies reported by Haïssaguerre et al (5) and Nam et al $(6,7)$.

The early repolarization hypothesis could be explained in terms of ionic and cellular mechanisms. The ionic and cellular mechanisms associated with generation of an early repolarization pattern are similar to those responsible for $\mathbf{J}$ wave manifestation and ST-segment elevation in Brugada syndrome (BrS) (4). A net outward shift in the balance of the current active in the early phases of the epicardial action potential (AP), which is secondary to reduction of $\mathrm{I}_{\mathrm{Ca}}$ or $\mathrm{I}_{\mathrm{Na}}$ or augmentation of $\mathrm{I}_{\mathrm{K}-\mathrm{ATP}}$, has been demonstrated to underlie the early repolarization ECG pattern and substrate responsible for the development of life-threatening arrhythmias associated with early repolarization syndrome (ERS) (8-12).

The delayed depolarization hypothesis could be expressed as follows. An SCN5A loss-of-function mutation leads to reduced sodium current, which may in turn decrease the Vmax of the membrane AP and thus reduce membrane excitability. This may result in conduction delays. The conduction delay between the right ventricular apex (RVa) and right ventricular outflow tract (RVot) generates the $\mathrm{BrS}$ coved-type ECG.

However, debates on the mechanism underlying $\mathbf{J}$ wave syndrome including BrS and ERS have been ongoing for decades (13). Theoretically, both the two mechanisms-delayed depolarization theory and early repolarization theory are feasible. Recently, Haïssaguerre et al (14) defined ERS with/without a conduction delay. In other words, they described 
both ERS with delayed depolarization and ERS with early repolarization.

The delayed depolarization theory may be explained by regional conduction velocity heterogeneity in the ventricular myocardium (15). Thus, if polymorphic ventricular tachycardia (pVT) develops without any regional conduction velocity heterogeneity, it would be less compatible with the delayed depolarization. The aim of the present study was to identify whether pVT could develop without regional conduction velocity heterogeneity. In the present study, the transmural conduction time was evaluated at several transmural locations using a canine ERS wedge preparation model.

\section{Materials and methods}

Wedge preparations and electrogram recordings. All experiments were conducted in accordance with the guidelines for the management and use of laboratory animals by the Institutional Animal Care and Use Committee. The study was approved by the Animal Care and Use Committee at Chonnam National University, Gwangju, Republic of Korea (approval number, CNU IACUC-H-2017-33). Detailed methods for the wedge isolation and electrogram recording from coronary-perfused canine left ventricle (LV) wedge preparations have previously been reported $(16,17)$. The animals were supplied by Orient Bio, Inc. Briefly, adult mongrel dogs (age, $\sim 1$ year-old, weight, $20-35 \mathrm{~kg}$; 9 males, 9 females) underwent anticoagulation with heparin (300 units/kg IV) and were anesthetized with pentobarbital (30-35 mg/kg IV). The chest was opened via a left thoracotomy, and the heart was excised and placed in a cardioplegic solution [cold $\left(4^{\circ} \mathrm{C}\right)$ Tyrode's solution containing $12 \mathrm{mmol} / 1 \mathrm{KCl}$ ]. Death of the animal was confirmed by personnel trained to recognize cessation of vital signs in euthanasia. The wedge preparations $\left(2.2-2.4 \times 2.0-2.2 \times 1.8-1.9 \mathrm{~cm}^{3}\right)$ were transmurally dissected from the inferolateral free wall of the LV. The second or third diagonal artery ostium was cannulated using a handmade small plastic cannula and fixed using a thread, while the cardioplegic solution [Tyrode's solution containing $\mathrm{NaCl}(129 \mathrm{mM}), \mathrm{KCl}(12 \mathrm{mM}), \mathrm{NaH}_{2} \mathrm{PO}_{4}(0.9 \mathrm{mM})$, NaHCO3 (20 mM), CaCl2 (1.8 mM), MgSO4 (0.5 mM) and glucose $(5.5 \mathrm{mM})]$ was delivered via the cannula. Non-perfused tissue was carefully cut using a razor blade. After being placed in a tissue bath, Tyrode's solution containing $\mathrm{KCl}(4 \mathrm{mM})$ was delivered using a roller pump (Cole Parmer Instrument Co., Ltd.) at a constant flow rate of $8-10 \mathrm{ml} / \mathrm{min}$ and warmed to $37 \pm 0.5^{\circ} \mathrm{C}$. The temperature was maintained at $37 \pm 0.5^{\circ} \mathrm{C}$ throughout the experiment. The $\mathrm{pH}$ was 7.4.

The preparation was equilibrated in the tissue bath until electrically stabilized for $\sim 1 \mathrm{~h}$, while being stimulated at a cycle length of 1,000 msec using bipolar silver electrodes, insulated up to the tips. The preparations were stimulated endocardially. A transmural pseudo-ECG was obtained using two electrodes, consisting of $\mathrm{AgCl}$ half cells placed in the tissue bath. The tip of the two electrodes were placed along the same axis as the transmembrane AP recordings. The distance between endocardial or epicardial surface and the pseudo-ECG electrode was $1.0-1.5 \mathrm{~cm}$; the epicardial electrode was connected to the positive input of the ECG amplifier.

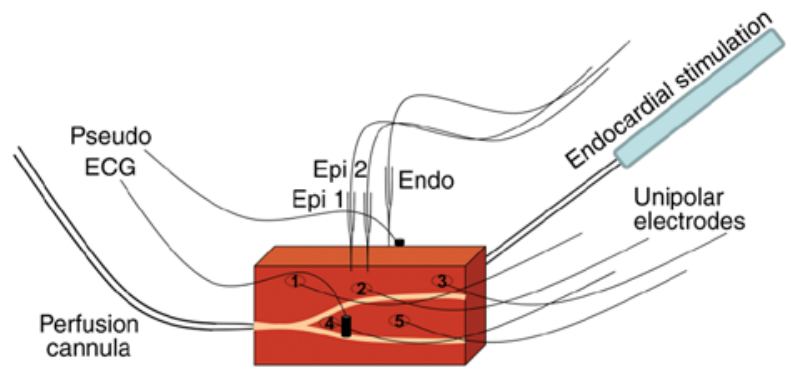

Figure 1. Schematic image of a left ventricular canine coronary-perfused wedge preparation indicating the recording electrodes used. Transmembrane action potentials were acquired simultaneously from two epicardial sites and one endocardial site using floating microelectrodes. A pseudo-ECG was acquired using two $\mathrm{AgCl}$ electrodes placed across the preparation. Five unipolar electrodes were evenly distributed on the epicardial surface. ECG, electrocardiogram; Endo, endocardial; Epi, epicardial.

The transmembrane APs were acquired simultaneously from two epicardial sites (distance from epicardial 1 to 2 was $5-10 \mathrm{~mm}$ ) and one endocardial site using floating microelectrodes (DC resistance=10-20 M 2 ) filled with $2.7 \mathrm{~mol} / 1$ $\mathrm{KCl}$; each microelectrode was connected to a high-input impedance amplifier. Five unipolar electrodes (1, 2, 3, 4 and 5) were evenly distributed on the epicardial surface (Fig. 1). Each individual microelectrode had its own reference electrode at the shortest possible distance. The virtual bipolar electrograms were derived as the difference of the adjacent two unipolar electrograms (1-2, 2-3, 1-4, 2-4, 2-5 and 3-5 pairs).

Measurement of the transmural conduction time. Spike2 for Windows version 7 (Cambridge Electronic Design Ltd.) was used to record and analyze ECGs, electrograms and APs. All electrograms and analyses were manually checked by three independent observers. The transmural conduction time was defined as the time from the endocardial pacing to the maximal negative deflection $(\mathrm{d} V / \mathrm{d} t)$ of the signal at the unipolar electrode. The transmural conduction times were measured prior to the perfusion of provocative agents and immediately before pVT development at the five fixed epicardial unipolar electrodes and two fixed epicardial floating microelectrodes. The transmural conduction times at these seven fixed transmural locations were evaluated. Conduction time dispersion was defined as the difference between the longest and the shortest conduction time.

Arrhythmia induction. The ERS model setup and arrhythmia induction procedure were conducted according to the previously reported methods $(3,9)$. To produce the pharmacologically similar ERS genotypes, the $\mathrm{I}_{\text {to }}$ agonist NS5806 (9-10 $\mu \mathrm{M})$, calcium channel blocker verapamil $(2 \mu \mathrm{M})$ and acetylcholine (ACh; $2 \mu \mathrm{M}$ ) were added to the perfusate. All preparations were endocardially stimulated at a cycle length of 1,000 msec. When ventricular arrhythmias occurred spontaneously after the perfusion of provocative agents, this was referred to as arrhythmia inducibility.

Statistical analysis. For continuous variables, a paired Student's t-test was used to analyze differences between 


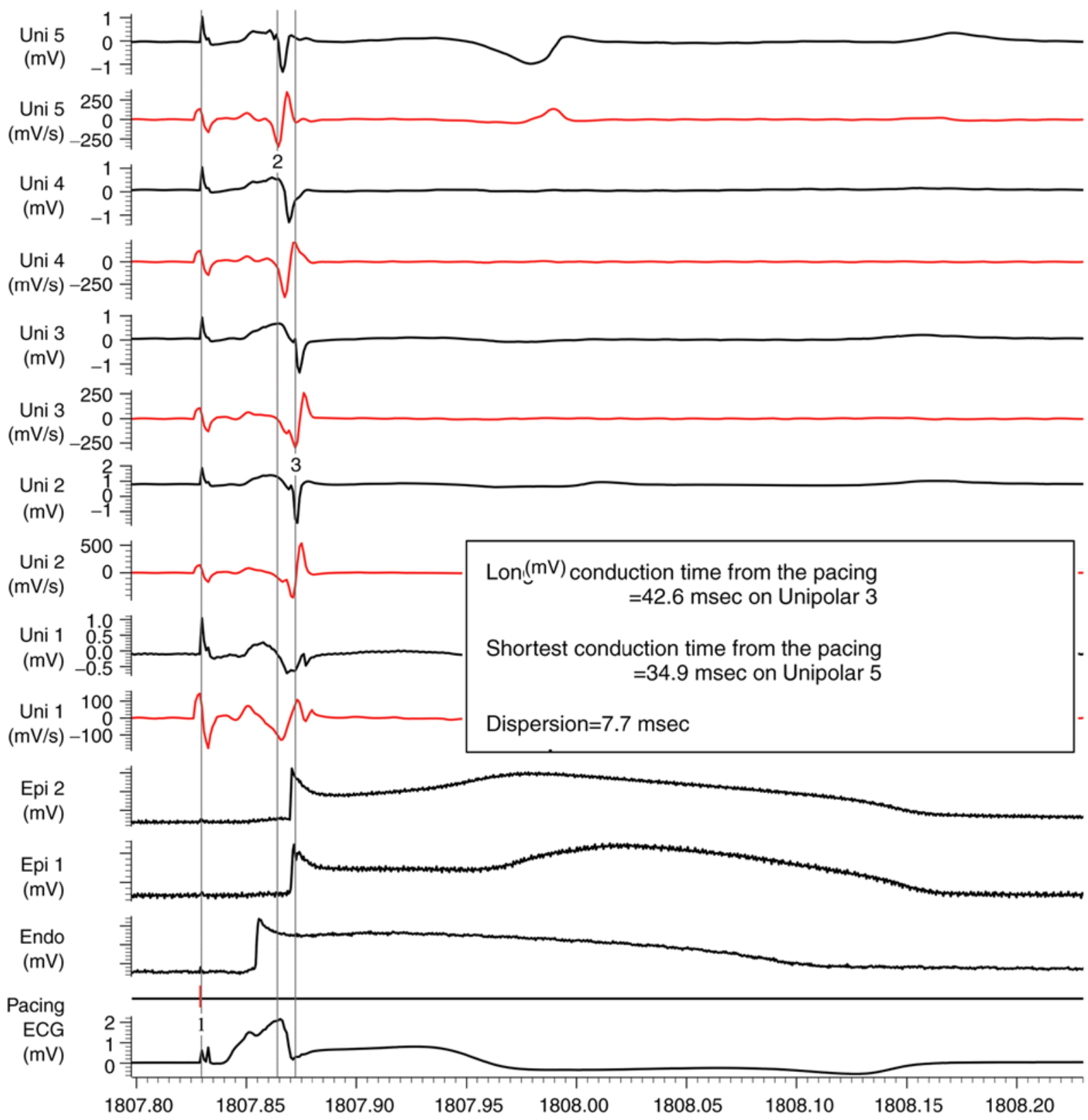

Figure 2. Transmural conduction time was defined as the time from endocardial pacing to the maximal negative deflection (dV/d t) of the signal at the unipolar electrode. APs, action potentials; ECG, electrocardiogram; Endo, endocardial; Epi, epicardial; Uni, unipolar electrode.

the before and after the provocative agents. For statistical analyses, the Statistical Package for the Social Sciences 25.0 software (IBM corp.) was used. Data are described as mean \pm standard error of the mean (SEM). A two-tailed analysis was used, and a P-value of $<0.05$ indicated statistical significance.

\section{Results}

The transmural pseudo-ECG and endocardial/epicardial APs were recorded in the coronary-perfused canine left ventricular wedge preparations $(n=18)$. All preparations were endocardially stimulated at a cycle length of $1,000 \mathrm{msec}$. The transmural conduction time and the dispersion were measured. As indicated in Fig. 2, the longest conduction time on Unipolar 3 was $42.6 \mathrm{msec}$ and the shortest conduction time on Unipolar 5 was
$34.9 \mathrm{msec}$. Thus, the transmural conduction time dispersion was $7.7 \mathrm{msec}$ in the preparation.

Coronary-perfusates of $\mathrm{I}_{\mathrm{to}}$ agonist, calcium channel blocker and ACh were used to induce a state similar to the genetic defects and conditions known to be associated with ERS. In the present study, the ERS model was induced in 14/18 preparations. Under baseline conditions, the ECG did not show a marked $J$ wave and augmentation of the AP notch was not seen in the epicardial sites (Fig. 3A). In the ECG, marked $\mathrm{J}$ waves with ST-segment elevation were induced by the $\mathrm{I}_{\mathrm{to}}$ agonist NS5806 $(9-10 \mu \mathrm{M}), \mathrm{Ca}^{2+}$ channel blocker verapamil $(2 \mu \mathrm{M})$, and ACh $(2 \mu \mathrm{M})$, secondary to augmentation of the AP notch in the epicardium but not in the endocardium. For example, the maintained dome at the epicardial 1 electrode and loss of the dome at the epicardial 2 electrode were identified (Fig. 3B). It resulted in phase 2 re-entry (P2R) (Fig. 3B). 


Baseline $\quad$ NS5806 $(7 \mu \mathrm{M})+$ Verapamil $(3 \mu \mathrm{M})+\mathrm{ACh}(2 \mu \mathrm{M})$

A

Bi 4-5

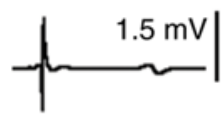

Bi 3-5

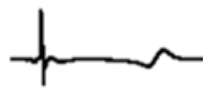

Bi $2-5$

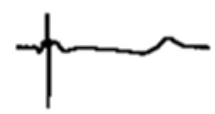

Bi $2-4$

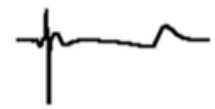

Bi 1-4

Bi 2-3

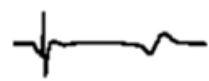

Bi 1-2
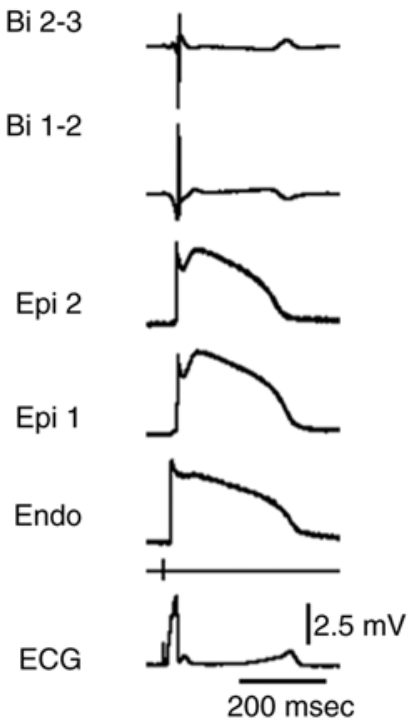

B
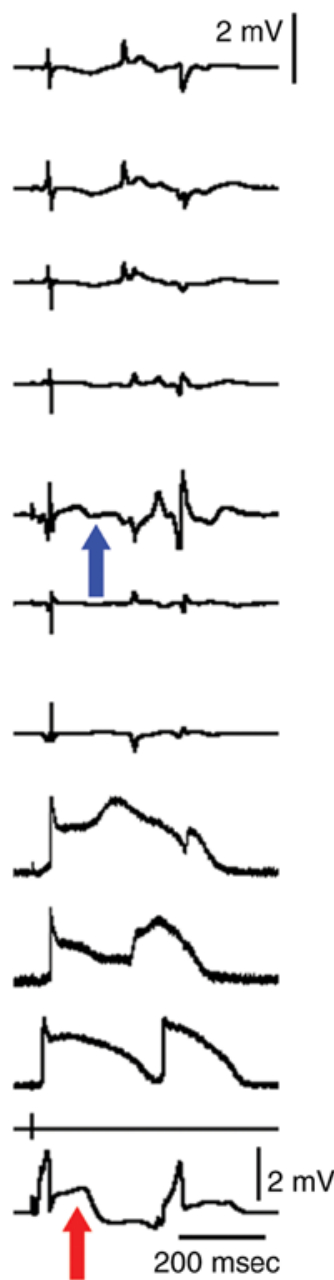

C
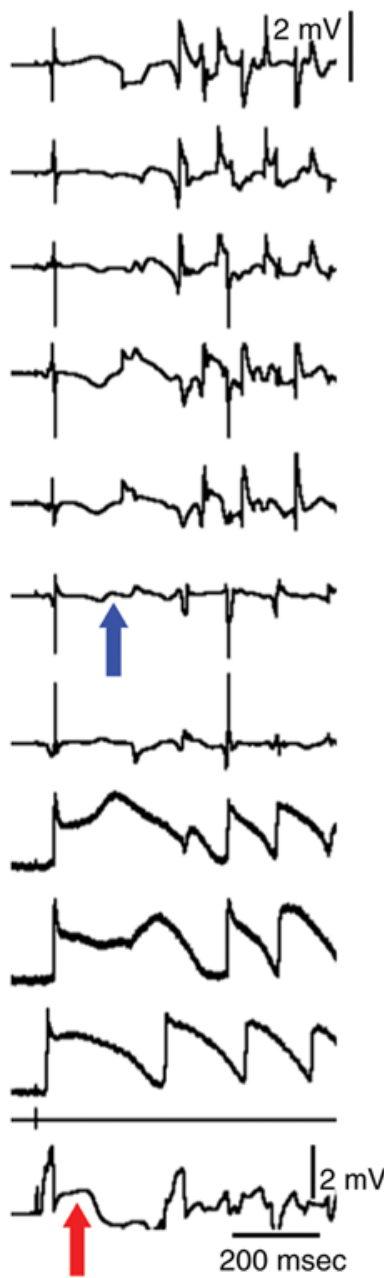

D
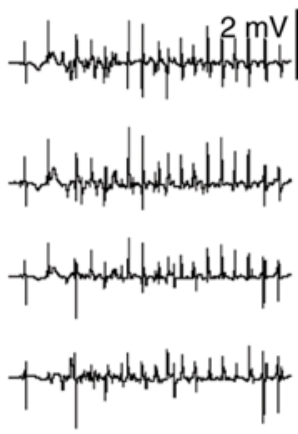

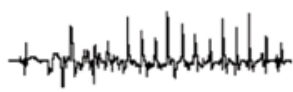
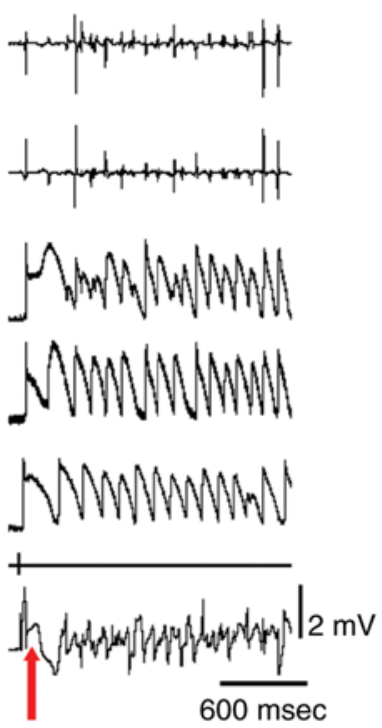

Figure 3. Experimental model of ERS created using a combination of the Ito agonist (NS5806), calcium channel blocker (verapamil) and ACh to mimic the genetic defects and conditions known to be associated with ERS. (A) Baseline. (B) Recorded during stimulation of the endocardium at a BCL of 1,000 msec at 20 min after the addition of the provocative agents to the coronary perfusate. Note the appearance of a pronounced ST-segment elevation (red arrows) in the ECG, low amplitude fractionated bipolar electrogram activity (Bi 1-4, Bi 2-3; blue arrows) secondary to epicardial AP maintained dome and loss-of-dome and phase 2 reentry. The epicardial reentry induced a single echo to the endocardium. (C) Then, the P2R propagated to the endocardium and precipitated pVT. The pVT sustained for 1-2 sec in the beginning. (D) The pVT continued for more than 30 sec. APs, action potentials; Bi, bipolar electrode; ECG, electrocardiogram; Endo, endocardial; Epi, epicardial; pVT, polymorphic ventricular tachycardia; ACh, acetylcholine.

Successful propagation of the P2R beat generated VT/VF on the electrograms in Fig. 3C. The pVT sustained for 1-2 sec in the beginning and sustained for more than $30 \mathrm{sec}$ (Fig. 3D). The pVTs developed in 14/18 preparations. Slight 'delayed' phase 0 upstrokes of the transmembrane AP occurred in the preparations. Increases in the conduction delay were 3.2 \pm 2.9 and $1.8 \pm 2.8 \mathrm{msec}$ for the epicardial glass microelectrodes 1 and 2 , respectively.

The transmural conduction time, during which the impulse propagated from the endocardial pacing site to each epicardial site (two epicardial glass microelectrodes and five epicardial unipolar electrodes), increased significantly after the $\mathrm{I}_{\text {to }}$ agonist NS5806 $(9-10 \mu \mathrm{M}), \mathrm{Ca}^{2+}$ channel blocker verapamil $(2 \mu \mathrm{M})$ and Ach $(2 \mu \mathrm{M})$ were perfused (Fig. 4; Table I). The mean increase in the conduction time before and after the perfusion of provocative agents was $2.6 \pm 0.4 \mathrm{msec}$. However, dispersion of the transmural conduction time did not exhibit any significant difference $(7.16 \pm 0.93 \mathrm{msec}$ vs. $7.76 \pm 1.21 \mathrm{msec}$; $\mathrm{P}=0.240$; Fig. 5).

\section{Discussion}

ERS is associated with the gain-of-function mutations in the pore-forming subunit of the ATP-sensitive potassium channel $(K C N J 8)(10,12)$, loss-of-function mutations in the $\alpha 1$, $\beta 2$, and $\alpha 2 \delta$ subunits of the cardiac L-type calcium channel (CACNA1C, CACNB2 and CACNA2D1) (11), and loss-of-function mutations in the sodium channel activity ( $S C N 5 A)(18)$. Moreover, the greater vulnerability of the inferior wall of LV to early repolarization has been ascribed to the presence of a higher density of the transient outward current $\left(I_{t o}\right)(9)$. Both the electrocardiographic and arrhythmic features of ERS are 


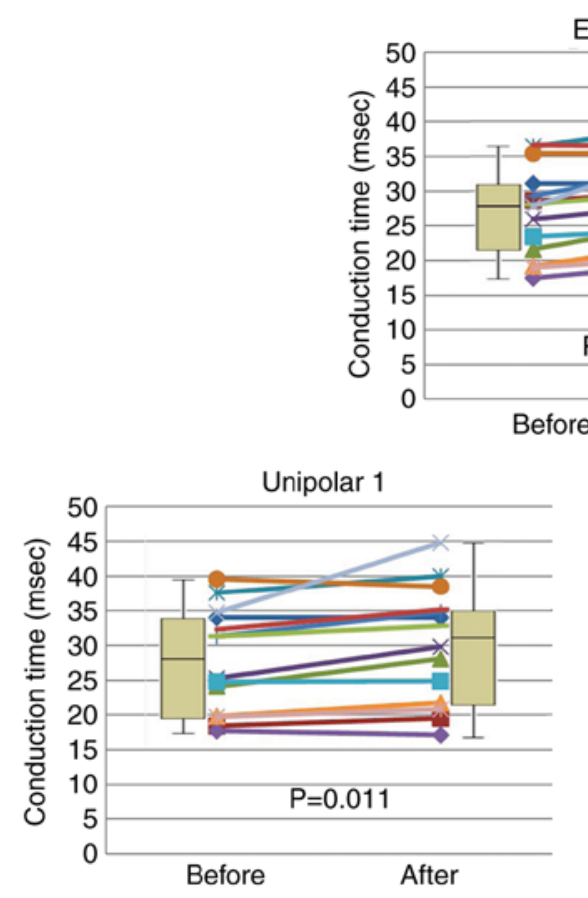

Epicardial 1

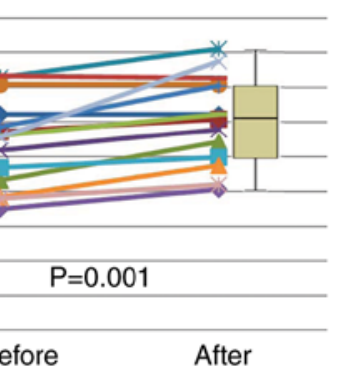

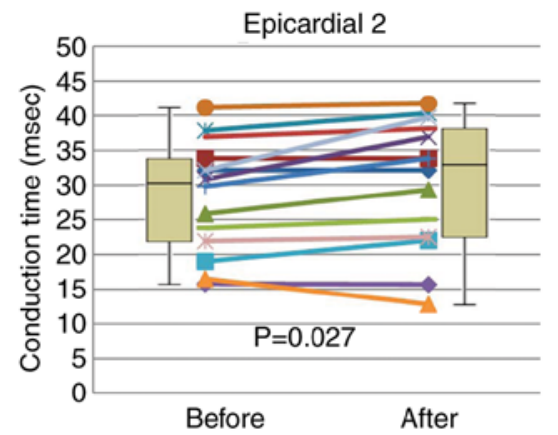
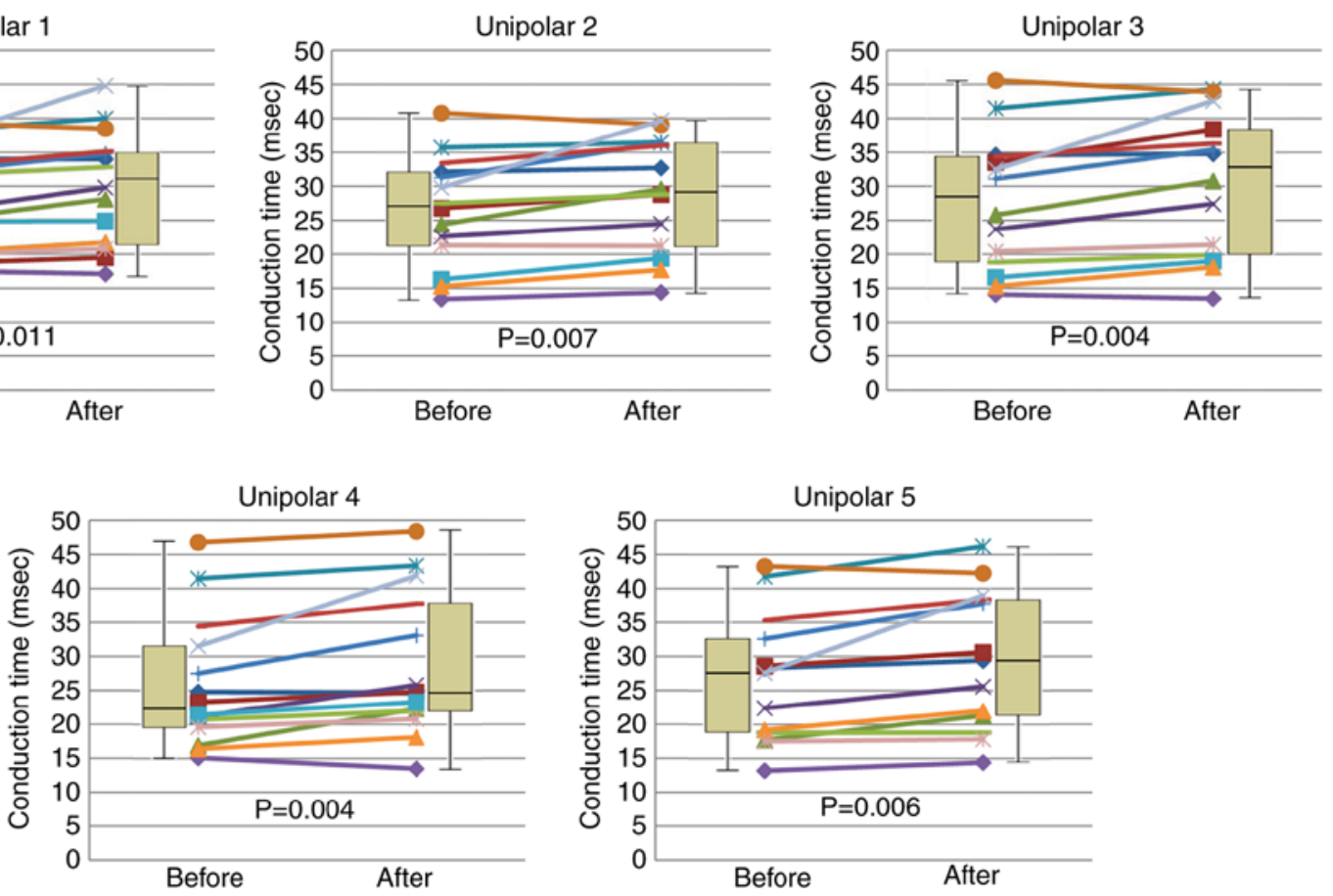

Figure 4. Serial plotting of the transmural conduction time during which the impulse propagates from the endocardial pacing site to each epicardial site (two epicardial glass microelectrodes and five epicardial unipolar electrodes) before and after the provocative agents [NS5806 $(9-10 \mu \mathrm{M})$, verapamil $(2 \mu \mathrm{M})$ and acetylcholine $(2 \mu \mathrm{M})]$ were perfused. The yellow boxes are boxplots of the conduction time. The transmural conduction time increased significantly after the Ito agonist verapamil and acetylcholine were perfused. The mean difference in the conduction time before and after perfusion was $2.6 \pm 0.4 \mathrm{msec}$.

enhanced by vagal influences (19-24). Thus, a pharmacological approach was used in the present study to produce ERS-related conditions and genetic defects. Several agents were used, such as NS5806 for increased $\mathrm{I}_{\mathrm{to}}$ current, verapamil for the loss-of-function mutation in the calcium channel activity and ACh for increased vagal tone $(4,8,17)$.

According to the depolarization abnormality theory of $\mathrm{BrS}$, the syndrome develops due to a difference in the conduction time between the RVot (25) and RVa, and a $200 \mathrm{msec}$ difference in the conduction time is necessary (26). This may be regarded as a longitudinal conduction time difference; however, the longitudinal conduction time is different from the transmural conduction time reported in the present study (endocardial to epicardial conduction time). Therefore, it may be illogical to explain the arrhythmogenicity of $\mathrm{BrS}$ using the results of the present transmural conduction time study. However, in certain examples of ERS reported in a study by Haïssaguerre et al (14), the epicardial depolarization wavefront did not cross the $\mathbf{J}$ wave onset. This means that the local conduction delay is shorter and, thus, local conduction time dispersion is small.
Therefore, the result of the present study demonstrated JWS without a conduction delay, which was previously classified by Haïssaguerre et al (14). It was identified that arrhythmia reported in the present study was induced spontaneously, without conduction time heterogeneity. Di Diego et al (27) reported that there was no significant conduction delay between the RVot and RVa in their canine whole heart Langendorff model of BrS.

In the present experiment, the $\mathrm{I}_{\mathrm{to}}$ agonist NS5806 (9-10 $\mu \mathrm{M}), \mathrm{Ca}^{2+}$ channel blocker verapamil $(2 \mu \mathrm{M})$ and Ach $(2 \mu \mathrm{M})$ induced prominent $\mathbf{J}$ waves due to the transmural voltage gradients. In brief, $\mathrm{K}^{+}$efflux by the $\mathrm{I}_{\mathrm{to}}$ agonist and $\mathrm{Ca}^{2+}$ influx by the $\mathrm{Ca}$ channel blocker were involved in epicardial repolarization due to the dense distribution of $\mathrm{I}_{\mathrm{to}}$ in the epicardium. It was hypothesized that the P2R was induced by regional AP loss of dome and maintained dome in the epicardium (Fig. 3B). This phenomenon is associated with heterogeneous shortening of the epicardial action potential duration (APD). Eventually, transepicardial heterogeneity induced a transmural voltage gradient and precipitated VT/VF. Koncz et al (9) reported the 
Table I. Transmural conduction time during which the impulse propagates from the endocardial pacing site to each epicardial site ( 2 epicardial glass microelectrodes and 5 epicardial unipolar electrodes) before $(n=14)$ and after $(n=14)$ the provocative agents were perfused.

\begin{tabular}{lccc}
\hline Electrode & $\begin{array}{c}\text { Transmural conduction time } \\
\text { before treatment, msec }\end{array}$ & $\begin{array}{c}\text { Transmural conduction time } \\
\text { after treatment, msec }\end{array}$ \\
\hline Glass electrode 1 & $27.1 \pm 1.7$ & $30.3 \pm 1.7$ & 0.001 \\
Glass electrode 2 & $28.3 \pm 2.1$ & $30.2 \pm 2.5$ & 0.027 \\
Unipolar 1 & $27.9 \pm 1.9$ & $30.1 \pm 2.3$ & 0.011 \\
Unipolar 2 & $26.4 \pm 2.1$ & $28.9 \pm 2.2$ & 0.007 \\
Unipolar 3 & $27.7 \pm 2.6$ & $30.4 \pm 2.8$ & 0.004 \\
Unipolar 4 & $25.7 \pm 2.5$ & $28.5 \pm 2.8$ & 0.004 \\
Unipolar 5 & $26.6 \pm 2.6$ & $29.5 \pm 2.9$ & 0.006 \\
Dispersion & $7.16 \pm 0.93$ & $7.76 \pm 1.21$ & 0.240 \\
\hline
\end{tabular}

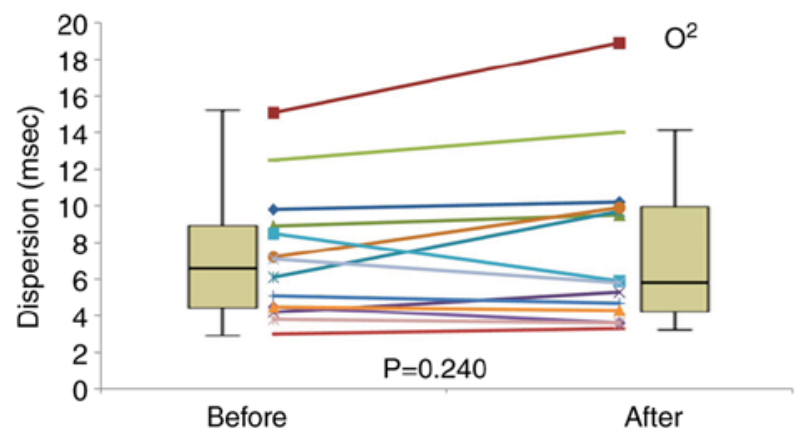

Figure 5. Comparison of the dispersion of transmural conduction time. Conduction time dispersion was defined as the difference between the longest and shortest conduction time. The transmural conduction time increased significantly. However, dispersion of the transmural conduction time did not exhibit a significant difference $(7.16 \pm 0.93 \mathrm{msec}$ vs. $7.76 \pm 1.21 \mathrm{msec} ; \mathrm{P}=0.240)$.

heterogeneous shortening of $\mathrm{APD}_{90}$ in the same model. According to our previous study, the QT interval was only prolonged by $13 \mathrm{msec}$, and the value did not contribute to the occurrence of ventricular arrhythmia (28). Moreover, the results of the present study indicated that there was no significant difference in the QT interval when compared to the baseline state.

Assuming that the ERS is generated by delayed depolarization or early repolarization, one of the key factors is a voltage gradient $(8,13,14)$. In all theories, a great enough voltage gradient is required to induce reentrant arrhythmia. In the present study, the mean increase in the transmural conduction time after perfusing the provocative agents was only $2.6 \pm 0.4 \mathrm{msec}$, which was notably smaller than the $200 \mathrm{msec}$ suggested by Wilde et al (26). This would be insufficient to create a steep transmural voltage gradient to generate arrhythmia. However, in the present experiment, the transmural dispersion of repolarization (TDR) was very long. For example, the TDR in Fig. 3B was $200 \mathrm{msec}$. The epicardial 1 electrode had a short APD and the endocardial electrode had a long APD, which induced a large TDR (200 msec). In the example presented in Fig. 3, the phase 2 voltage gradient between the endocardium and epicardium is very steep. This was sufficient to create a huge $\mathbf{J}$ wave including ST elevation (red arrows in Fig. 3).
If the $\mathrm{J}$ wave in ERS is generated due to temporal difference in the AP, a sufficient temporal delay of the AP should exist between the endocardium and epicardium. Therefore, the degree of temporal difference (conduction velocity difference in other words) should be, at least the same as, or larger than, the length of the $\mathrm{J}$ wave. When this concept was applied to the present experiment, it may have been possible to induce a very small $\mathrm{J}$ wave about $2.6 \mathrm{msec}$ long. However, it was near impossible to induce large $\mathrm{J}$ waves, as revealed in Fig. 3B, which was recognized just before the development of VT/VF because there was not a sufficiently delayed phase 0 upstroke in the transmembrane AP recording, in any of the preparations. The delay was not enough to cause a steep transmural voltage gradient required to generate a reentrant arrhythmia.

As aforementioned, epicardial heterogeneity serves an important role in the occurrence of ventricular arrhythmias $(29,30)$. If a sufficient temporal difference in the AP exists at the local epicardium sites, it may serve a role in the formation of arrhythmia substrates. Typically, an epicardial temporal difference in the AP increases the dispersion of the conduction time (31). The transmural conduction time, despite being very short, during which the impulse propagated from the endocardial pacing site to each epicardial site (two epicardial glass microelectrodes and five epicardial unipolar electrodes), increased significantly in the present experiments. However, dispersion of the transmural conduction time did not exhibit a significant difference (Fig. 5). Thus, this finding indicated that there was a homogeneous conduction delay.

Srinivasan et al (32) addresses that interventricular dispersion of the repolarization generates a voltage gradient for arrhythmias (33). However, we hypothesize that this theory also has an insufficient probability of being able to explain the creation of a steep transmural voltage gradient $(34,35)$.

The present study supports the concept that ECG patterns of ERS and pVT can be reproduced by difference in the local repolarization, without heterogeneous conduction delay. However, the current results do not suggest that local depolarization heterogeneity is not associated with the underlying mechanism of ERS, because multiple factors (including autonomic nerve tones) seemed to be involved in 
the development of ERS. A whole-heart global conduction, such as between RVot and RVa, was not demonstrated in the present study. Therefore, the role of global depolarization heterogeneity cannot be excluded when explaining the mechanism underlying ERS. The results of the present study may be used as a basis to establish the appropriate pharmacologic treatments for ERS. For example, several agents such as phosphodiesterase III inhibitors and flavonoids are being studied $(36,37)$.

The wedge preparation model with a pharmacologically induced ERS phenotype is representative of a denervated heart. Thus, the model is in an autonomically denervated state. The canine wedge preparation model cannot reflect the global physiology of the whole heart. Notably, the use of whole heart Langendorff models would overcome this limitation.

Polymorphic ventricular tachycardia was induced in the canine wedge preparation ERS model without regional conduction velocity heterogeneity. This suggests that local depolarization heterogeneity would not greatly contribute to the generation of ERS with no conduction delay. However, the role of global conduction delay in ERS cannot be denied. Hence, demonstration of global conduction delay of action potentials using a whole heart Langendorff model or human heart is needed in further studies.

\section{Acknowledgements}

We are grateful to the late Professor Jae Ha Kim (Medical School, Chonnam National University, Korea) for the experimental support. We gratefully acknowledge Mr. John Martin (Japan Lifeline Co., Ltd., Japan) for linguistic assistance with the manuscript.

\section{Funding}

No funding was received.

\section{Availability of data and materials}

The datasets used and/or analyzed during the current study are available from the corresponding author on reasonable request.

\section{Authors' contributions}

NY was a major contributor in writing the manuscript and contributed to the design, literature search, experimental studies, data acquisition, data analysis, manuscript preparation, manuscripts editing, manuscript review, approval of the final version of the manuscript and agreed to all aspects of the work. HKJ contributed to the literature search, experimental studies, data analysis, statistical analysis, manuscripts editing, manuscript review, approval of the final version of the manuscript and agreed to all aspects of the work. KHL contributed to the literature search, statistical analysis, manuscript review, approval of the final version of the manuscript and agreed to all aspects of the work. HWP contributed in the conception of the work, manuscript review, approval of the final version of the manuscript and agreed to all aspects of the work. JGC contributed in the conception of the work, definition of intellectual content, manuscripts editing, manuscript review, approval of the final version of the manuscript and agreed to all aspects of the work. All authors read and approved the final manuscript.

\section{Ethics approval and consent to participate}

All experiments were performed in accordance with the Guide for Care and Use of Laboratory Animals published by the National Institutes of Health (38) and all experiments were approved by the Animal Care and Use Committee at Chonnam National University, Gwangju, Republic of Korea (approval number, CNU IACUC-H-2017-33).

\section{Patient consent for publication}

Not applicable.

\section{Competing interests}

The authors declare that they have no competing interests.

\section{References}

1. Wasserburger RH and Alt WJ: The normal RS-T segment elevation variant. Am J Cardiol 8: 184-192, 1961

2. Mehta MC and Jain AC: Early repolarization on scalar electrocardiogram. Am J MedSci 309: 305-311, 1995.

3. Gussak I and Antzelevitch C: Early repolarization syndrome: Clinical characteristics and possible cellular and ionic mechanisms. J Electrocardiol 33: 299-309, 2000.

4. Antzelevitch C and Yan GX: J wave syndromes. Heart Rhythm 7: 549-558, 2010.

5. Haissaguerre M, Derval N, Sacher F, Jesel L, Deisenhofer I, de Roy L, Pasquié JL, Nogami A, Babuty D, Yli-Mayry S, et al: Sudden cardiac arrest associated with early repolarization. N Engl J Med 358: 2016-2023, 2008.

6. Nam GB, Kim YH and Antzelevitch C: Augmentation of J waves and electrical storms in patients with early repolarization. $\mathrm{N}$ Engl J Med 358: 2078-2079, 2008.

7. Nam GB, Ko KH, Kim J, Park KM, Rhee KS, Choi KJ, Kim YH and Antzelevitch C: Mode of onset of ventricular fibrillation in patients with early repolarization pattern vs. brugada syndrome. Eur Heart J 31: 330-339, 2010.

8. Antzelevitch C: J wave syndromes: Molecular and cellular mechanisms. J Electrocardiol 46: 510-518, 2013.

9. Koncz I, Gurabi Z, Patocskai B, Panama BK, Szél T, Hu D, Barajas-Martínez H and Antzelevitch C: Mechanisms underlying the development of the electrocardiographic and arrhythmic manifestations of early repolarization syndrome. J Mol Cell Cardiol 68: 20-28, 2014.

10. Hu D, Barajas-Martinez H, Terzic A, Park S, Pfeiffer R, BurashnikovE, Wu Y, Borggrefe M, Veltmann C, Schimpf R, et al: ABCC9 is a novel Brugada and early repolarization syndrome susceptibility gene. Int J Cardiol 171: 431-442, 2014.

11. Burashnikov E, Pfeiffer R, Barajas-Martinez H, Delpón E, Hu D, Desai M, Borggrefe M, Häissaguerre M, Kanter R, Pollevick GD, et al: Mutations in the cardiac L-type calcium channel associated with inherited J-wave syndromes and sudden cardiac death. Heart Rhythm 7: 1872-1882, 2010.

12. Barajas-Martinez H, Hu D, Ferrer T, Onetti CG, Wu Y, Burashnikov E, Boyle M, Surman T, Urrutia J, Veltmann C, et al: Molecular genetic and functional association of brugada and early repolarization syndromes with S422L missense mutation in KCNJ8. Heart Rhythm 9: 548-555, 2012.

13. Di Diego JM and Antzelevitch C: Inferolateral J-wave syndromes: A reflection of abnormal repolarization, depolarization, or both? Heart Rhythm 16: 791-792, 2019.

14. Haissaguerre M, Nademanee K, Hocini M, Cheniti G, Duchateau J, Frontera A, Sacher F, Derval N, Denis A, Pambrun T, et al: Depolarization versus repolarization abnormality underlying inferolateral J-wave syndromes: New concepts in sudden cardiac death with apparently normal hearts. Heart Rhythm 16: 781-790, 2019. 
15. Veerakul G and Nademanee K: Brugada syndrome: Two decades of progress. Circ J 76: 2713-2722, 2012.

16. Fish JM, Welchons DR, Kim YS, Lee SH, Ho WK and Antzelevitch C: Dimethyl lithospermate B, an extract of danshen, suppresses arrhythmogenesis associated with the brugada syndrome. Circulation 113: 1393-1400, 2006.

17. Di Diego JM, Sicouri S, Myles RC, Burton FL, Smith GL and Antzelevitch C: Optical and electrical recordings from isolated coronary-perfused ventricular wedge preparations. J Mol Cell Cardiol 54: 53-64, 2013.

18. Watanabe H, Nogami A, Ohkubo K, Kawata H, Hayashi Y, Ishikawa T, Makiyama T, Nagao S, Yagihara N, Takehara N, et al: Electrocardiographic characteristics and SCN5A mutations in idiopathic ventricular fibrillation associated with early repolarization. Circ Arrhythm Electrophysiol 4: 874-881, 2011.

19. Mizumaki K, Nishida K, Iwamoto J, Nakatani Y, Yamaguchi Y, Sakamoto T, Tsuneda T, Kataoka N and Inoue H: Vagal activity modulates spontaneous augmentation of $\mathrm{J}$-wave elevation in patients with idiopathic ventricular fibrillation. Heart Rhythm 9: 249-255, 2012

20. Wilhelm M, Brem MH, Rost C, Klinghammer L, Hennig FF, Daniel WG and Flachskampf F: Early repolarization, left ventricular diastolic function, and left atrial size in professional soccer players. Am J Cardiol 106: 569-574, 2010.

21. Marcus RR, Kalisetti D, Raxwal V, Kiratli BJ, Myers J, Perkash I and Froelicher VF: Early repolarization in patients with spinal cord injury: Prevalence and clinical significance. J Spinal CordMed 25: 33-38, 2002.

22. Koutbi L, Roussel M, Haissaguerre M and Deharo JC: Hyperpnea test triggering malignant ventricular arrhythmia in a child with early repolarization. Heart Rhythm 9: 1153-1156, 2012.

23. Kawata H, Noda T, Yamada Y, Okamura H, Satomi K, Aiba T, Takaki H, Aihara N, Isobe M, Kamakura S and Shimizu W: Effect of sodium-channel blockade on early repolarization in inferior/lateral leads in patients with idiopathic ventricular fibrillation and brugada syndrome. Heart Rhythm 9: 77-83, 2012.

24. Kasanuki H, Ohnishi S, Ohtuka M, Matsuda N, Nirei T, Isogai R, Shoda M, Toyoshima Y and Hosoda S: Idiopathic ventricular fibrillation induced with vagal activity in patients without obvious heart disease. Circulation 95: 2277-2285, 1997.

25. Meregalli PG, Wilde AA and Tan HL: Pathophysiological mechanisms of brugada syndrome: Depolarization disorder, repolarization disorder, or more? Cardiovasc Res 67: 367-378, 2005.

26. Wilde AA, Postema PG, Di Diego JM, Viskin S, Morita H, Fish JM and Antzelevitch C: The pathophysiological mechanism underlying brugada syndrome: Depolarization versus repolarization. J Mol Cell Cardiol 49: 543-553, 2010.

27. Di Diego JM, Argenziano $M$, Chen K, Tabler $M$ and Antzelevitch C: In a whole-heart model of the brugada syndrome, delayed conduction in the RVOT 'does not' contribute to inscription of the electrocardiographic J wave/ST segment elevation. Heart Rhythm 15: 242, 2018.
28. Yoon N, Hong SN, Cho JG, Jeong HK, Lee KH and Park HW: Experimental verification of the value of the $\mathrm{T}_{\text {peak }}-\mathrm{T}_{\text {end }}$ interval in ventricular arrhythmia inducibility in an early repolarization syndrome model. J Cardiovasc Electrophysiol 30: 2098-2105, 2019.

29. Antzelevitch C, Yan GX and Shimizu W: Transmural dispersion of repolarization and arrhythmogenicity: The brugada syndrome versus the long QT syndrome. J Electrocardiol 32: $158-165,1999$.

30. Maoz A, Christini DJ and Krogh-Madsen T: Dependence of phase-2 reentry and repolarization dispersion on epicardial and transmural ionic heterogeneity: A simulation study. Europace 16: 458-465, 2014

31. Sims JJ, Miller AW and Ujhelyi MR: Electrical heterogeneity and arrhythmogenesis: Importance of conduction velocity dispersion. J Cardiovasc Pharmacol 41: 795-803, 2003.

32. Srinivasan NT, Orini M, Providencia R, Simon R, Lowe M, Segal OR, Chow AW, Schilling RJ, Hunter RJ, Taggart P and Lambiase PD: Differences in the upslope of the precordial body surface ECG T wave reflect right to left dispersion of repolarization in the intact human heart. Heart Rhythm 16: 943-951, 2019.

33. Malik M, Huikuri HV, Lombardi F, Schmidt G, Verrier RL and Zabel M; e-Rhythm Group of EHRA: Is the $T_{\text {peak }}-T_{\text {end }}$ interval as a measure of repolarization heterogeneity dead or just seriously wounded? Heart Rhythm 16: 952-953, 2019.

34. Antzelevitch C and Di Diego JM: Reply to the editor- $\mathrm{T}_{\text {peak }}-\mathrm{T}_{\text {end }}$ is alive and well. Heart Rhythm 16: e49-e50, 2019.

35. Antzelevitch C and Di Diego JM: $T_{\text {peak }}-T_{\text {end }}$ interval as a marker of arrhythmic risk. Heart Rhythm 16: 954-955, 2019.

36. Patocskai B, Barajas-Martinez H, Hu D, Gurabi Z, Koncz I and Antzelevitch C: Cellular and ionic mechanisms underlying the effects of cilostazol, milrinone, and isoproterenol to suppress arrhythmogenesis in an experimental model of early repolarization syndrome. Heart Rhythm 13: 1326-1334, 2016.

37. Yoon N, Hong SN, Lee KH, Park HW and Cho JG: Antiarrhythmic effect of artemisinin in brugada syndrome model. Europace 20: i138, 2018.

38. Clark JD, Gebhart GF, Gonder JC, Keeling ME and Kohn DF Special report: The 1996 guide for the care and use of laboratory animals. ILAR J 38: 41-48, 1997.

This work is licensed under a Creative Commons Attribution 4.0 International (CC BY-NC 4.0) License 